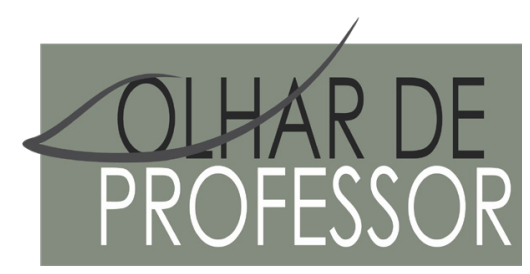

DOI: 10.5212/OLHARPROFR.v.22.0014

\title{
A PEDAGOGIA UNIVERSITÁRIA E A FORMAÇ̃̃o DO PROFESSOR DE MATEMÁTICA: UMA ANÁLISE DO PROJETO PEDAGÓGICO DO CURSO DA UFMS/CPTL
}

\author{
ACADEMIC PEDAGOGY AND MATHEMATICS TEACHER TRAINING: AN ANALYSIS OF THE PEDAGOGICAL \\ PROJECT OF THE MATHEMATICS UFMS/CPTL COURSE
}

\section{LA PEDAGOGIA UNIVERSITARIA Y LA FORMACIÓN DEL PROFESOR DE MATEMÁTICA: UN ANÁLISIS DEL PROYECTO PEDAGÓGICO DEL CURSO DE LA UFMS/CPTL}

\author{
PAULO FIORAVANTE GIARETA* \\ EUGENIA BRUNILDA OPAZO URIBE* \\ GERSON DOS SANTOS FARIAS ${ }^{\text {** }}$
}

\begin{abstract}
Resumo: O artigo discute a formação do professor de matemática, a partir da análise do Projeto Pedagógico do Curso ofertado na UFMS - Universidade Federal de Mato Grosso do Sul, CPTL - Campus de Três Lagoas. A pesquisa vincula as categorias de ensino, pesquisa e extensão, inerentes à pedagógica universitária, às categorias saberes docentes, prática e identidade docentes, amplamente evidenciadas como características da formação de professores por autores como Shulman (1986), Fiorentini et al (1998), Tardif (2002). O trabalho responde pelo objetivo de elucidar o alcance das referidas categorias, como proposta político-pedagógica do curso universitário de formação dos professores de matemática. Metodologicamente, a pesquisa se estrutura como exercício dialético, por meio da Análise de Conteúdo. A pesquisa aponta para uma caracterização genérica da proposta de formação de professores no Curso de Matemática da UFMS/CPTL, advinda de ambiguidades teóricas e metodológicas.
\end{abstract}

Palavras-Chave: Formação de professores. Curso de Matemática. Projeto Pedagógico.

\begin{abstract}
The article discusses the mathematics teacher training, based on the analysis of the Pedagogical Project of the Course offered at UFMS - Federal University of Mato Grosso do Sul, CPTL - Três Lagoas Campus. The research links the teaching, research and extension categories inherent in the academic pedagogy, to the teaching knowledge, practice and identity categories, widely evidenced as characteristics of teacher education, by authors such as Shulman (1986), Fiorentini et al (1998), Tardif (2002). The work responds to the purpose of clarifying about the reach of these categories, as a political-pedagogical proposal of the university mathematics teacher training course. Methodologically, the research is structured as a dialectical exercise, through content analysis. The research points to a generic characterization of the teacher training proposal of the UFMS/CPTL Mathematics Course, arising from theoretical and methodological ambiguities.
\end{abstract}

Keywords: Teacher Training. Math Course. Pedagogical Project.

Resumen: El artículo discute la formación del profesor de matemática, a partir del análisis del Proyecto Pedagógico del Curso ofrecido en la UFMS - Universidad Federal de Mato Grosso do Sul, CPTL - Campus de Três Lagoas.

\footnotetext{
* Doutor em Educação pela Universidade Federal do Paraná - UFPR. Professor da Universidade Federal de Mato Grosso do Sul - UFMS e do Programa de Pós-Graduação em Educação do Campus de Três Lagoas - PPGEdu/CPTL. pfgiareta27@yahoo. com.br

** Doutora em Engenharia Mecânica pela FEM/UNICAMP. Professora do Curso de Matemática da Universidade Federal de Mato Grosso do Sul - UFMS, Campus de Três Lagoas - CPTL. eugenia.uribe@ufms.br

*** Licenciado em Matemática pela Universidade Federal de Mato Grosso do Sul - UFMS, Campus de Três Lagoas - CPTL. Mestrando do Programa de Pós-Graduação em Educação Matemática da UFMS. gersonfarias14@hotmail.com
} 
La investigación vincula las categorías de enseñanza, investigación e extensión, inherentes a la pedagogía universitaria, a las categorías saberes docentes, práctica docente e identidad docente, ampliamente evidenciadas como características de la formación de profesores, por autores como Shulman (1986), Fiorentini (1998), Tardif (2002). El trabajo busca aclarar el alcance de las referidas categorías, como propuesta político-pedagógica del curso universitario de formación de los profesores de matemática. Metodológicamente, la investigación se estructura como ejercicio dialéctico, por medio del Análisis de Contenido. La investigación apunta hacia una caracterización genérica de la propuesta de formación de profesores en el Curso de Matemática de la UFMS/CPTL, que surge de ambigüedades teóricas y metodológicas.

Palabras-Chave: Formación de profesores. Curso de Matemática. Proyecto Pedagógico.

\section{INTRODUÇ̃̃O}

A adoção, pelo sistema de ensino, de indicadores de qualidade para a educação básica vinculados às avaliações externas, também denominadas de avaliações de larga escala, bem como a progressiva aposta no reformismo curricular como política capaz de qualificar os resultados da educação brasileira, projeta grande expectativa sobre a área da linguagem matemática, tida como determinante para os índices de qualidade.

Essa expectativa tem incidência direta sobre a formação do professor, especialmente a formação inicial, tornando-a objeto constante de pesquisas, debates e, até mesmo, de cobranças institucionalizadas.

É neste contexto que o presente trabalho, vinculado ao GForP - Grupo de Estudos e Pesquisa em Fromação de Professores, objetiva contribuir, a partir da análise do Projeto Pedagógico do Curso ofertado pela Universidade Federal de Mato Grosso do Sul - Campus de Três Lagoas (UFMS-CPTL), com a produção de conhecimento científico sobre a caracterização político-pedagógica da formação de professores de matemática a partir da pedagogia universitária.

O trabalho, metodologicamente, está vinculado à concepção dialética histórica enquanto “exercício situado no plano da realidade, no plano da história, sob a forma da trama de relações contraditórias, conflitantes, de leis de construção, desenvolvimento e transformação dos fatos” (FRIGOTTO, p. 75, 1997), bem como possibilidade teórica e instrumento lógico de interpretação da realidade, sendo capaz de indicar um caminho epistemológico para o exercício da interpretação da proposta em análise (BENITE, 2009).

Ao se propor analisar o Projeto Pedagógico do Curso, documento institucional que regula legalmente a oferta dos cursos no âmbito da universidade e sua pedagogia adotada, a partir da concepção dialética histórica, a pesquisa demanda o aporte da Análise do Conteúdo, enquanto técnica de análise das comunicações, indicando os significados das mensagens através de uma descrição objetiva, sistemática e quantitativa do conteúdo (BARDIN, 2002).

A Análise de Conteúdo se estruturou, no presente trabalho, a partir das fases carátéristicas desta técnica: a pré-analise, a exploração do material e o tratamento dos resultados, conforme indicado por Bardin (2002).

Destaca-se, ainda, que o trabalho recebe os suportes teóricos de autores como Fiorentini et al (1998), Tardif (2002) e Shulman (1986). Shulman (1986), inclusive, fornece, de forma articulada categorias inerentes à pedagogia universitária - ensino, pesquisa e extensão -, as categorias de análise do trabalho. Sendo assim, as categorias de análise deste trabalho se dividem em: Concepção de Ensino, interligada aos Saberes Docentes e Conteúdos Específicos; Concepção de Pesquisa, ligada à Prática Docente e ao Conteúdo Pedagógico; e Concepção de Extensão, conectada à Identidade Docente e ao Conteúdo Curricular.

O texto se estrutura a partir de dois exercícios. O primeiro busca construir as categorias de análise por meio do debate com autores que tratam da formação de professores e, posteriormente, de posse destas cotegorias, o segundo analisa, de fato, o Projeto Político Pedagógico do Curso de Matemática da UFMS/CPTL. 


\section{AS INTENCIONALIDADES POLÍTICO-PEDAGÓGICAS DA FORMAÇ̃̃O DE PROFESSORES: A BUSCA POR CATEGORIAS DE ANÁLISE.}

A atividade de ensino na escola básica, também a do ensino de matemática, exige, do professor, tanto conhecimentos do conteúdo a ser ensinado quanto das metodologias de ensino. O modo de articulação dessas ações do professor não corresponde a uma construção mecânica e homogênea, mas sim em constante evolução e desenvolvimento ao longo da formação e da prática docente (RANGEL et al, 2014).

Essa articulação tem despertado intensas discussões e pesquisas, especialmente, na perspectiva da relação teoria e prática, que ainda se apresenta profundamente marcada por limitações quanto às especificidades do processo formativo no ambiente universitário e da atuação docente no espaço da escola básica. O conhecimento científico ministrado nos espaços acadêmicos tende a apresentar um distanciamento, por exemplo, da linguagem a ser ensinada nas escolas, indicando não ser suficiente a apropriação isolada de um conjunto de conceitos teóricos ou de conhecimentos metodológicos acessados durante a graduação.

A formação do professor, na perspectiva da articulação teoria e prática, dar-se-á por inúmeros fatores, visto que a construção da identidade docente para o exercício do ofício se constitui na complexidade da junção de saberes e práticas. Palhano (1995) ajuda a compreender que, além dos conhecimentos específicos, a formação do professor é constituída por meio de suas experiências ao longo da vida. Os determinantes históricos, que afetam a apropriação dos conhecimentos e a compreensão da prática do professor, não podem ser acomodados na simples transmissão dos conhecimentos já constituídos, mas pressupõem compreender a formação como um processo complexo de inter-relações no espaço social e político.

Para Fiorentini et al (1998) a vinculação das relações teórico-práticas, mediadas pela complexidade político-pedagógica, na formação do professor, aproxima-nos de categorias de saberes e conhecimentos, as quais são indicadas também por Tardif (2002) ao reconhecer que estas categorias abrangem competências, habilidades e atitudes, isto é, muitas vezes chamadas, respectivamente, de saber, saber-fazer e saber-ser.

A afirmativa de que a articulação teoria e prática é uma conquista do professor, construída ao longo do tempo na medida em que aperfeiçoa a sua prática, também vale para as denominadas categorias saberes e conhecimentos, que respondem como intencionalidades político-pedagógicas construídas diariamente e por meio de constante atualização no processo de formação e prática do professor.

Segundo Gauthier et al (1998), os saberes docentes são adquiridos para o trabalho, ou no trabalho, e mobilizados para o ensino/trabalho do professor com uma reflexão prática de sua ação docente, resolvendo situações, mediando relações e deliberando ações, levando em conta a individualidade e pluralidade de cada sujeito.

Na articulação teoria e prátca, agora identificada, também, pelas categorias saberes e conhecimentos, para Fiorentini et al (1998), o professor se constrói em um núcleo de saberes e percepções, de maneira contínua e coletiva, utilizando a prática pedagógica como problematização, significação e exploração dos conteúdos de formação, repensando diariamente seu trabalho na perspectiva da formação humana e seu papel ético-político-pedagógico.

Esta constatação é potencializada, por Shulman (1986; 1987), ao ressaltar que a construção das relações do saber docente não se dá apenas pela transmissão de conteúdos já pré-estabelecidos por currículos, mas sim pelas diferentes relações de saberes construídos entre professor/aluno/ambiente escolar, uma vez que o saber/conhecimento não é algo imútavel, todavia é constituído por um conjunto de elementos sociais, éticos, políticos, culturais, afetivos e emocionais. E, se tratando da formação do professor inserido neste meio, Shulman (1986) destaca que o conhecimento do conteúdo pode ser dividido em três categorias: conteúdo específico, conteúdo pedagógico e conteúdo curricular.

Seguindo a abordagem do autor, o conhecimento específico potencializa o professor a dominar o conteúdo a ser trabalhado em sala de aula e suas demandas exigidas por determinados assuntos, pois a matemática possui uma série de particularidades para a construção do saber matemático, a ser articulado e construído gradativamente.

O conhecimento pedagógico, por sua vez, perpassa um conjunto de saberes não restritos ao traquejo da matéria/conteúdo específico, mas capaz de articular ao conteúdo curricular, movimentos de exemplificação, ilustração, demonstração, em síntese, fala sobre o modo de se ensinar. 
Por fim, ainda sobre a influênica de Shuman (1986), o conhecimento do conteúdo curricular se refere às disciplinas ministradas pelo professor: estruturas, organização, livros didáticos, materiais de apoio institucional e suas demandas.

Saviani (1996) também contribui com o exercício de explicitar as intencionalidades político-pedagógicas da formação do professor ao destacar que na relação dos saberes com a prática emergem saberes atitudinais, saberes crítico-conceituais, saberes específicos, saberes pedagógicos e saberes didático-curriculares. Embora apresente uma categorização dos saberes e conhecimentos em caráter mais detalhado, na prática, o autor corrobora com as categorizações já indicadas, reafirmando as características norteadoras do processo de formação do professor, aqui, especificamente, do professor de matemática.

Contudo, este processo, na formação do professor de matemática, não se apresenta de forma linear e pacífica. Um conjunto de contradições permeia todo o processo formativo, que pode ser expresso por indagações, conforme demonstrado a seguir: (i) como se dá a constituição e/ou reconstituição dos saberes do professor de Matemática na transição da formação inicial aos primeiros anos de docência?; (ii) quais saberes científicos, adquiridos durante a Licenciatura, são mobilizados nesse processo, durante o exercício da ação docente?; e (iii) a identidade docente se constitui para além da formação acadêmica e dos saberes decorrentes da prática docente?

O esforço de elucidar as dimensões norteadoras para a formação de professores permite, ainda, questões sobre quais categorias o professor que ensina matemática deve se apropriar? O que leva autores, como Tardif, Lessard \& Lahaye (1991, p. 218), a reconhecer que o saber docente é "um saber plural, formado pelo amálgama, mais ou menos coerente, de saberes oriundos da formação profissional, dos saberes das disciplinas, dos currículos e da experiência”.

É, portanto, um saber complexo, composto por um conjunto de elementos, envolvendo profissionais inseridos em diferentes contextos sócio-histórico-culturais. Isto é, suas trajetórias de vida repercutem diretamente no processo de construção da identidade desse professor.

A partir desta perspectiva, é possível identificar os professores como técnicos e como profissionais (HABERMAS, 1989), pois o exercício da profissão gera tensões entre as identidades pessoal e profissional, o que pode conduzir à compreensão de uma espécie de cobrança em torno do ser um bom professor, questionando inúmeras situações, pensamentos, sentimentos e intuições em relação ao papel do profissional inserido em sala de aula, marcado pela transição de sua condição de aluno à condição de professor.

Segundo Habermas (1989) os professores como técnicos se preocupam exclusivamente na transmissão do conhecimento científico, adquiridos em cursos e institutos, por meio da linguagem da racionalidade técnica. Por outro lado, os professores como profissionais buscam desenvolver nos alunos a capacidade de pensamento crítico e responsabilidade cívica, o que acaba exigindo deste professor flexibilidade, criatividade e atenção continuada aos processos de investigação.

A referida intencionalidade político-pedagógica encontra respaldo no sistema educacional brasileiro, na pedagogia universitária, ou seja, na pedagogia que acomoda as iniciativas formativas para os docentes da matemática. É atribuída à universidade, e consequentemente, à pedagogia universitária, a capacidade de desenvolver uma relação dialógica mediadora dos sujeitos cognitivos em torno ao objeto de estudo e da prática social, aqui, referendadas como conhecimentos, saberes e competências necessárias à formação docente (GIARETA, 2017).

Os anunciados pressupostos educacionais se articulam à própria concepção de formação universitária, legitimando a reclamada indissocabiliade entre ensino, pesquisa e extensão, como movimento teórico-metodológico norteador dessa pedagogia e, concomitantemente, da busca pela indissociável articulação entre saberes, práticas e identidade na formação do professor de matemática, enquanto condição político-pedagógica para a atuação docente. Princípios formativos que teóricos aclamam a partir da integralidade das dimensões técnica, pedagógica e política (MASETTO, 1998), ou, congnitivas, sociais e políticas (CUNHA, 2011) e, ainda, dimensão técnica, científico-pedagógica e sócio-política da formação de professores (GIARETA, 2017).

Esta postura pedagógica guarda a expectativa de uma proposta formativa para além da mera qualificação centrada na transmissão de conteúdos pré-definidos, mas também, capaz de promover a vinculação a partir das dimensões ténica, científico-pedagógica e sócio-política da formação do professor 
de matemática, sem se desvincular das indicadas categorias de saberes, prática e identidade docentes. Considerações que motivam o estudo do Projeto Pedagógico do Curso (PPC) de Licenciatura em Matemática da Universidade Federal de Mato Grosso do Sul - Campus de Três Lagoas (UFMS-CPTL), a partir das categorias mencionadas anterioremente neste texto.

\section{AS INTENCIONALIDADES POLÍTICO-PEDAGÓGICAS DA FORMAÇ̃̃O DE PROFESSORES: UM OLHAR SOBRE O PPC DE MATEMÁTICA.}

O Curso de Matemática da UFMS - CPTL obteve reconhecimento oficial através da Resolução $\mathrm{n}^{\circ} 19$, COUN, de 7 de julho de 1986, sendo implantado no ano seguinte e reconhecido pela Portaria $\mathrm{n}^{\circ}$ 1.023, MEC, de 26 de outubro de 1990.

A Resolução no 2 do Conselho Nacional de Educação (CNE), aprovada e homologada em 2015, traduzindo os esforços da Comissão Bicameral, articulada aos dispositivos legais e as demandas formalizadas na Conferência Nacional de Educação, CONAE, de 2010 e de 2014; e o Plano Nacional de Educação de 2014, com vigência até 2024, viabilizaou a aprovação de novas diretrizes curriculares para a formação inicial em nível superior e para a formação continuada.

Essas novas diretrizes preveem impacto direto sobre os Projetos Pedagógicos dos Cursos de formação de professores no âmbito das instituições de ensino superior. Neste quesito, o Curso de Licenciatura em Matemática da unidade de Três Lagoas da UFMS, objeto de análise do presente trabalho, atendendo as diretrizes estabelecidas pela Resolução $n^{\circ}$ 2, também promoveu adequações em seu PPC.

O referido PPC reafirma o seu objetivo com a formação profissional inicial de professores de Matemática para o Ensino Básico ( $6^{\circ}$ ao $9^{\circ}$ ano do ensino fundamental e todos os anos do ensino médio) por meio de uma sólida formação pedagógica e em Matemática que permita o entendimento abrangente do papel de educador com capacidade de trabalhar em equipes multidisciplinares (UFMS, 2019).

O alcance e a caracterização deste objetivo, no âmbito da proposta formativa da universidade, estão articulados e garantidos pelo próprio PPC ao figurar como documento capaz de sintetizar as intencionalidades político-pedagógicas do curso, estruturado a partir das dimensões de concepção do curso de graduação, as quais consistem em: fundamentos da gestão pedagógica e administrativa, perfil dos formandos, competências e habilidades, conteúdos curriculares de formação geral e os conteúdos de formação específica, formato dos estágios e das atividades complementares, estrutura e formas de avaliação do Curso.

A capacidade de orientar a proposta formativa do curso atribuída ao PPC implica a necessidade de vinculá-lo à presente pesquisa, como documento norteador das categorias/concepções de ensino, pesquisa e extensão, ilustrativas dos necessários saberes, práticas e identidade docentes, aqui, apresentados como características centrais no processo de formação do professor que ensina matemática.

Assim, a análise do PPC de Matemática objetiva elucidar a referida caracterização pela leitura detalhada do projeto por meio das categorias ensino, pesquisa e extensão, enquanto categorias inerentes à pedagogia universitária que acomodam e regulamentam a oferta do Curso.

\section{REPRESENTAÇ̃̃O INICIAL DAS CATEGORIAS ENSINO, PESQUISA E EXTENÇÃO NO PPC}

O modo de manifestação das categorias ensino, pesquisa e extensão no PPC de Licenciatura em Matemática possibilita, de imediato, perceber uma disparidade, a qual indica grande valorização à categoria ensino e a expressiva desvalorização das categorias pesquisa e extensão, apontando para indícios de desarticulação entre teoria e prática na formação inicial dos futuros professores, conforme mostrado no gráfico 1. 
GRÁFICO 1: QUUANTIDADE DE MENÇÕES POR CATEGORIAS

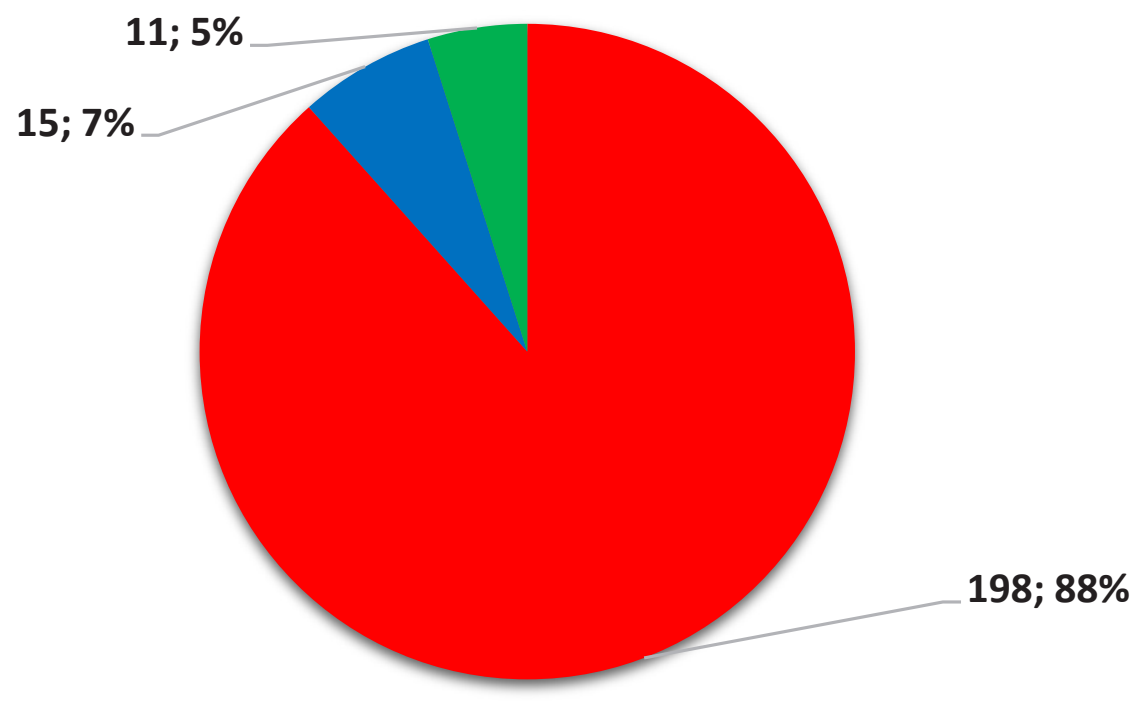

Ensino Pesquisa Extensão

FONTE: ORGANIZADA PELOS AUTORES,

Com base no gráfico, é possível identificar que as menções à categoria ensino correspondem a $88 \%$, restando apenas $15,7 \%$ para a Pesquisa e $11,5 \%$ para a extensão. Ou seja, fica evidente a preocupação do PPC com a dimensão ensino, demandando um olhar detalhado sobre o PPC em busca da melhor compreensão e pontuais caracterizações das outras respectivas categorias citadas.

\section{CATEGORIA ENSINO}

A leitura cuidadosa do Projeto Pedagógico do Curso de Licenciatura em Matemática da UFMS/ CPTL busca a identicação do modo de apresentação da categoria ensino, relacionada ao conteúdo específico proposto por Shulman (1986), cuja disposição detém de 198 menções ao longo do texto, como constatado no quadro 1. 
QUADRO 1: CATEGORIA ENSINO

\begin{tabular}{|c|c|c|}
\hline $\begin{array}{c}\text { Seções do PPC em que aparece o } \\
\text { conceito Ensino }\end{array}$ & Subseções do PPC em que aparece o conceito Ensino & Total \\
\hline 1. Identificação do Curso & $\begin{array}{l}\text { 1.5. Modalidade de ensino: Presencial } \\
\text { 1.13. Forma de ingresso }\end{array}$ & 3 \\
\hline 2. Fundamentação Legal & & 2 \\
\hline 3. Contextualização & 3.1. Histórico da UFMS & 8 \\
\hline 4. Necessidade Social do Curso & $\begin{array}{l}\text { 4.1. Indicadores socioeconômicos da população da mesorregião } \\
\text { 4.3. Análise da oferta do curso na região }\end{array}$ & 8 \\
\hline 5. Concepção do Curso & $\begin{array}{c}\text { 5.1.1 Técnica } \\
5.1 .2 \text { Política } \\
\text { 5.3. Estratégias para integração das diferentes componentes } \\
\text { curriculares } \\
\text { 5.4. Perfil desejado do egresso } \\
5.5 \text { Objetivos } \\
\text { 5.6 Metodologias de ensino } \\
\text { 5.7. Avaliação }\end{array}$ & 30 \\
\hline 6. Administração Acadêmica do Curso & $\begin{array}{l}\text { 6.1. Atribuições do colegiado do curso } \\
\text { 6.4. Organização acadêmico-administrativa } \\
\text { 6.5. Atenção aos discentes }\end{array}$ & 18 \\
\hline 7. Currículo & $\begin{array}{c}\text { 7.1. Matriz curricular do curso } \\
\text { 7.2. Quadro de semestralização } \\
\text { 7.3. Tabela de equivalência das disciplinas } \\
\text { 7.6. Bibliográgia básica e complementar } \\
\text { 7.7. Política de implementação da nova matriz currilar }\end{array}$ & 97 \\
\hline 8. Políticas & $\begin{array}{l}\text { 8.1. Capacitação do corpo docente } \\
\text { 8.4. Atendimento aos requisitos legais e normativos: Relações } \\
\text { étnico-raciais, direitos humanos e educação ambiental }\end{array}$ & 3 \\
\hline 9. Sistema de Avaliação & 9.1. Sistema de avaliação do processo formativo & 2 \\
\hline $\begin{array}{l}\text { 10. Atividades Acadêmicas } \\
\text { Articuladas ao Ensino de Graduação }\end{array}$ & \begin{tabular}{|} 
10.1. Atividades orientadas de ensino \\
10.5. Estágio obrigatório e não obrigatório \\
10.7. Participação do corpo docente nas atividades acadêmicas \\
10.8. Práticas de ensino (específico para cursos de medicina) \\
10.9. Prática de ensino na área da saúde \\
10.10. Prática de ensino como componente curricular
\end{tabular} & 21 \\
\hline $\begin{array}{l}\text { 11. Desenvolvimento de Materiais } \\
\text { Pedagógicos }\end{array}$ & & 2 \\
\hline 12. Infraestrutura Necessária ao Curso & & 1 \\
\hline $\begin{array}{l}\text { 13. Plano de Incorporação dos } \\
\text { Avanços Tecnológicos para o Ensino } \\
\text { de Graduação }\end{array}$ & & 2 \\
\hline 15. Referências & & 1 \\
\hline Total de menções: 198 & & \\
\hline
\end{tabular}

FONTE: ORGANZADO PELOS AUTORES

É possível indicar, a princípio, uma relação contraditória no tratamento conferido à categoria ensino no PPC de Licenciatura em Matemática, ao mesmo tempo que fica visível sua afirmação como preocupação central da proposta formativa, o próprio documento toma expressiva posse do conceito sem explicitar seu alcance, parecendo, apenas, espelhar uma função formal.

A formalidade das menções à categoria ensino perpassa todo o documento, desde itens que tratam da Metodologia de Ensino, “o curso de Licenciatura em Matemática adotará diferentes metodologias de 
ensino fazendo uso, sempre que possível, das ferramentas de Comunicação e Informação disponíveis” (UFMS, 2019, p. 13), até os itens que abordam o Estágio Obrigatório Curricular, "atividade curricular obrigatória visando à complementação do processo de ensino e aprendizagem (UFMS, 2019, p. 48).

O caráter formal, portanto, indica a pouca preocupação do projeto pedagógico em expor o significado e o alcance conceitual da categoria, conferindo vasão a uma concepção mais técnica e apegada ao manejo dos saberes teóricos de forma dissociada à prática docente na formação do futuro professor de matemática. Por conseguinte, esta proposição é assumida pelo próprio projeto do curso ao definir que se espera formar o professor com “uma base sólida de conhecimentos e técnicas matemáticas” (UFMS, 2019, p. 11)

Nota-se, inclusive, o apego, do referido PPC, a uma adjetivação específica, ao ensino de algo, isto é, a caracterização própria de uma ciência, nesse caso, a Matemática. Acerca disso, ao definir o Perfil desejado do egresso, o documento posiciona, “considerando este contexto, o curso de Matemática - Licenciatura/CPTL deve garantir que seus egressos tenham: Uma base sólida de conhecimentos e técnicas matemáticas bem como sua prática pedagógica; Uma formação pedagógica voltada para o ensino de Matemática [...] (UFMS, 2019, p. 11).

O próprio conceito de prática pedagógica, aqui, parece condicionado a potencializar a função técnica do ensino, distanciando-se da fução pedagógico-cientifica na formação docente (GIARETA, 2017). A preocupação formativa expressa no documento demonstra a explicitação do ensino de uma ciência, o que, de certa forma, pode limitar a compreenssão em sua totalidade.

Assim, esta proposição tendencia certo distanciamento da categoria ensino ao campo das intencionalidades formativas do professor, o que acaba promovendo um deslocamento para repetições expressas matematicamente em aplicações operacionais, pautando mais a racionalidade técnica do que formativa:

Proposta de temas para atividades de ensino orientadas: 1. O Ensino de Matemática em contextos multidisciplinares; 2. Novas Tecnologias de Informação e Comunicação e o Ensino de Matemática; 3. Jogos e o Ensino de Matemática; 4. Arte e Ensino de Matemática; 5. História da Ciência e o Ensino de Matemática; 6. Educação Especial e o Ensino de Matemática; 7. Educação Ambiental e Ensino de Matemática. Outros eixos poderão ser desenvolvidos, desde que aprovados pelo Colegiado de Curso e envolvam, obrigatoriamente, o Ensino de Matemática (UFMS, 2019, p. 47).

O PPC evidencia, também, um movimento de aproximação do conceito de ensino às matrizes de competência e habilidade, propondo que o curso se comprometa em mobilizar saberes através de exercícios de ensino, objetivando o desenvolvimento de determinados comportamentos com potencial de aplicabilidade. Deste modo,

O futuro professor deve atentar para algumas funções básicas que nortearão o seu papel no processo de ensinar matemática. São elas: (...) Avaliador: Nesta função, deve utilizar instrumentos apropriados para buscar indícios e sinais de competências desenvolvidas pelos alunos, levando-os a ter consciência de suas conquistas, bem como de suas dificuldades diante do processo de aprendizagem (UFMS, 2019, p. 11).

Evidentemente, este fato parece mais aprofundar a matriz técnica, proposta pelo projeto em tela, do que promover processos complementares e integrados entres saberes, práticas e identidade na formação do professor de matemática (SHULMAN, 1986).

Além do caráter formal e da aproximação às matrizes de competência e habilidades, é possível identificar uma orientação genérica na forma de apresentação da categoria ensino ao longo do texto do PPC, figurando mais como uma exigência narrativa, para dar sentido textual a uma afirmação, do que como expressão de compromisso político-pedagógico do Curso. Portanto, o documento parece estar comprometido apenas em cumprir uma formalidade textual, demonstrado no recorte abaixo.

Divisão de Orientação à Gestão Acadêmica/Dioge/CDA/Prograd: é a unidade responsável por orientar as Coordenações de Curso e outros setores acadêmicos em procedimentos e normativas relativas ao ensino de graduação. Coordenadoria de Bibliotecas/CBI/Prograd: É a unidade responsável pelo acervo bibliográfico e audiovisual, tendo como objetivo prover 
informações ao ensino, pesquisa e a extensão da Universidade, por meio do planejamento, coordenação e procedimentos de atividades de coleta, tratamento, armazenamento, recuperação e disseminação da informação (UFMS, 2019, p. 15).

Convém salientar que o expressivo conjunto de menções da categoria ensino no Projeto Pedagógico do Curso não garante a percepção de qualquer preocupação com a caracterização e significação, dificultando a própria vinculação do curso com o compromisso de garantir, na formação do professor de matemática, o acesso ao conhecimento do conteúdo específico, na perspectiva proposta por Shulman (1986).

\section{CATEGORIA PESQUISA}

Na pedagogia universitária, a qual recebe centralidade na política de formação de professores no Brasil, conforme prevê o artigo 62 da Lei no 9394 de 1996, LDB - Lei de Diretrizes e Bases da Educação Nacional, a pesquisa responde como princípio educativo capaz de potencializar a formação pedagógica e científica do professor. Por meio desta proposição, fundamenta-se a concepção teórico-metodológica deste trabalho articulada aos autores como Fiorentini (1998), Tardif (2002) e Shulman (1986).

O PPC de Matemática do CPTL parece desconhecer a pertinência pedagógico-científica da categoria pesquisa, que, no comparativo com a categoria ensino, apresenta um reduzido número de menções, ou seja, não superando a 15 indicações, como se pode conferir no quadro 2.

QUADRO 2: CATEGORIA PESQUISA

\begin{tabular}{|c|c|c|}
\hline $\begin{array}{c}\text { Seções do PPC em que aparece o } \\
\text { conceito Pesquisa }\end{array}$ & Subseções do PPC em que aparece o conceito Pesquisa & Total \\
\hline 3. Contextualização & 3.3. Histórico do Curso & 1 \\
\hline 6. Administração Acadêmica do Curso & $\begin{array}{c}\text { 6.4. Organização acadêmico-administrativa } \\
\text { 6.5. Atenção aos discentes }\end{array}$ & 5 \\
\hline 7. Currículo & 7.6. Bibliografia básica e complementar & 6 \\
\hline 9. Sistema de Avaliação & $\begin{array}{c}\text { 9.1. Sistema de avaliação do processo formativo } \\
\text { 9.4. Projeto institucional de monitoramento e avaliação do curso }\end{array}$ & 2 \\
\hline $\begin{array}{c}\text { 11. Desenvolvimento de Materiais } \\
\text { Pedagógicos }\end{array}$ & 1 \\
\hline Total de menções: 15 & & \\
\hline
\end{tabular}

FONTE: ORGANZZADO PELOS AUTORES

Além de reduzida preocupação em mencionar a categoria pesquisa, o PPC de Licenciatura em Matemática parece repetir a estratégia indicada na categoria ensino, desobrigando-se de explicitar ou caracterizar o que se entende, no âmbito do curso, por pesquisa.

A falta de clareza com a definição e o delineamento de alcance do conceito de pesquisa pode resultar em profundo esvaziamento do papel da pesquisa, da reflexão e da investigação na formação do professor de matemática. Inclusive, a leitura e a análise detalhada do PPC apontam para uma defesa da formalidade no uso do conceito de pesquisa, materializada em traços como os que seguem,

A Coordenação de Gestão Acadêmica tem como função colaborar com a Direção da Unidade da Administração Setorial fazendo a gestão, coordenação e orientação de Professores e TécnicoAdministrativo e atividades didático-pedagógicas, colaborando com o levantamento das demandas do Curso quanto à distribuição de encargos docentes, levantamento de demandas de Professores para o curso, organizando o uso do espaço físico, divulgando e orientando os docentes quanto às diretrizes e normas relacionadas á área de ensino, pesquisa e extensão (UFMS, 2019, p. 17).

Portanto, o curso em questão responde por uma abordagem restrita, mais atenta para formalidades juridícas, pois até quando menciona o Programa de Educação Tutorial (PET), o Programa de Inicição 
à Docência (PIBID) e o Progama Institucional de Bolsas de Iniciação Científica (PIBIC), entre outros, em nenhum instante, materializa no PPC a preocupação de especificar como a pesquisa se comporta nos referidos programas.

Este caráter formal parece se mesclar com o aspecto mais genérico da menção da categoria pesquisa, apresentado no decorrer do texto como complemento narrativo, para indicar movimentos institucionais frente ao curso. Assim,

Cada professor deve ser responsável por solicitar à direção do Campus, através da Coordenação de Curso, os materiais necessários para o desenvolvimento da disciplina sob sua responsabilidade. Existem materiais pedagógicos mais simples e que podem ser desenvolvidos pelos próprios acadêmicos sob supervisão do professor responsável no decorrer da disciplina, bem como através de projetos de ensino, pesquisa e extensão, utilizando para isto o Laboratório de Ensino de Matemática. (UFMS, 2019, p.49)

O posicionamento adotado garante o fluxo do documento com o uso da categoria pesquisa de maneira a atender uma demanda textual, para contemplar narrativas, porém sem compromisso com a caracterização e a significação do conceito.

Isto resulta na constatação de que as menções à categoria pesquisa, no Projeto Pedagógico do Curso, não possibilitam perceber qualquer preocupação com a função educativa da pesquisa na proposta de formação do professor de matemática, restando, evidemente, uma desarticulação entre teoria e prática (FIORENTINI et al, 1998); entre saberes e conhecimentos (TARDIF, 2002); saberes, prática e identidade (SHULMAN, 1986); e as dimensões técnicas, pedagógico-cientíca e sócio-política (GIARETA, 2017).

Dito de outra forma, os já indicados limites de alcance e caraterização do conceito de ensino materializam-se também no conceito de pesquisa, indicando certa impossibilidade tanto de acessarmos o conteúdo específico necessário para a formação do professor de matemática, quanto os conhecimentos científicos, saberes e práticas necessários a fim de efetivar o processo de ensino e aprendizagem metodologicamente qualificado.

Nas palavras de Shulman (1986), um arsenal de formas alternativas de representação metodológica, as quais derivam, muitas vezes, da pesquisa, enquanto outras têm sua origem no saber da prática. Logo, isto nos leva, também, a analisar as potencialidades formativas que advém da categoria extensão.

\section{CATEGORIA EXTENSÃO}

A categoria extensão, por sua vez, recebe 11 menções no Projeto Pedagógico do Curso de Matemática, cujos dados estão representados no quadro 3 a seguir.

QUADRO 3: CATEGORIA EXTENSÃO

\begin{tabular}{|c|c|c|}
\hline $\begin{array}{c}\text { Seções do PPC em que aparece o } \\
\text { conceito Extensão }\end{array}$ & Subseções do PPC em que aparece o conceito Extensão & Total \\
\hline 3. Contextualização & 3.3. Histórico do Curso & 2 \\
\hline 6. Administração Acadêmica do Curso & $\begin{array}{l}\text { 6.4. Organização acadêmico-administrativa } \\
\text { 6.5. Atenção aos discentes }\end{array}$ & 5 \\
\hline 7. Currículo & 7.6. Bibliográfia básica e complementar & 1 \\
\hline $\begin{array}{l}\text { 10. Atividades Acadêmicas Articuladas ao } \\
\text { Ensino de Graduação }\end{array}$ & $\begin{array}{l}\text { 10.3. Atividades de extensão } \\
\text { 10.7. Participação do corpo docente nas atividades } \\
\text { acadêmicas }\end{array}$ & 2 \\
\hline $\begin{array}{l}\text { 11. Desenvolvimento de Materiais } \\
\text { Pedagógicos }\end{array}$ & & 1 \\
\hline \multicolumn{3}{|c|}{ Total de menções: 11} \\
\hline
\end{tabular}

FONTE: ORGANIZADO PELOS AUTORES 
A aproximação da categoria extensão com as definições inerentes à formação do professor de matemática, definidas por Shulman (1986), exige reconhecer a contribuição da extensão na articulação de teoria e prática, tendo em vista a construção da identidade docente. Mas, a análise do PPC aponta para uma estratégia recorrente na organização do documento: o não compromisso com a definição de alcance e caraterização das categorias analisadas. Bem como as outras categorias, anteriormente mencionadas, a categoria extensão também é conceituada, no documento analisado, de modo amplo e vago.

Não obstante, a categoria extensão recebe status de subitem no documento e sua explicitação é praticamente nula. As definições de alcance e caracterização da categoria extensão, no PPC de Licenciatura em matemática, apresentam-se inviabilizadas, fragilizando a própria definição do papel da extensão na formação de professores, objetivada por Shulman (1986). Deste modo, não há a compreensão da extensão como fator integrante e conferido à identidade do professor.

Sendo assim, não há lugar para, devidamente, estender a teoria, aprendida e produzida nas universidades, e as práticas metodológicas, vivenciadas pelos futuros professores, à docência de fato. Isto é, a extensão não faria parte do ato de lecionar no programa proposto pelo documento analisado. No entanto, vale ressaltar que tanto a teoria quanto a prática não estão exclusivamente relacionadas às universidades e vivências dos professores respectivamente.

\section{CONSIDERAÇÕES}

A análise do Projeto Pedagógico do Curso contribui, para a formação do professor de matemática, à medida que busca compreender como esse se apropria dos conhecimentos específico, pedagógico e curricular, reformulando-os em saber, prática e identidade docentes e, por fim, atrelando-os, formal e respectivamente, ao ensino, à pesquisa e à extensão.

A percepção detalhada do alcance político-pedagógico da proposta de formação do professor no Curso de Licenciatura de Matemática na UFMS/CPTL demandaria um olhar complementar entre as intencionalidades explicitadas no projeto de curso e um conjunto de estratégias movimentadas pela instituição e pelos professores.

Contudo, compreendendo o PPC como documento que acomoda oficialmente as intencionalidades político-pedagógicas objetivadas pelo curso, é possível concluir que não se tem adotado uma postura clara e transparente para a melhor formação possível do futuro professor de matemática graduado pela UFMS/CPTL.

Esta pesquisa evidencia a existência de uma visão generalista da categoria ensino, preocupada, essencialmente, com a transmissão de um conceito científico que priorize as competências/habilidades em detrimento da construção do saber docente. A categoria pesquisa, por sua vez, parece se comportar, no projeto pedagógico, de maneira pragmática, mais atenta às formalidades jurídicas que à sua função político-pedagógica. Por fim, essas ações adotadas no corpo do texto analisado potencializam, quase que totalmente, o esvaziamento da categoria extensão, consequentemente, inviabilizando a articulação teórico-prática na formação docente.

Assim, este trabalho indica um ganho significativo, do ponto de vista teórico, da compreensão dos movimentos formativos demandados aos futuros professores de matemática, aqui, representados pela necessidade de articulação entre teoria e prática (FIORENTINI et al, 1998); saberes e conhecimentos (TARDIF, 2002); saberes, prática e identidade (SHULMAN, 1986); e pela indissociabilidade entre as dimensões técnicas, pedagógico-científica e sócio-política (GIARETA, 2017).

Em virtude desta pesquisa, espera-se que estes ganhos teóricos não encontrem dificuldades para se efetivarem nos processos legais políticos e pedagógicos de formação de professores, visto que, por meio desta discussão, observou-se uma demanda progressiva de cursos abertos que precisam de pesquisas e debates que objetivem esta necessária articulação entre ensino, pesquisa e extensão.

Nossa sugestão consiste em indicar e reafirmar o campo de estudos da pedagogia universitária como o lócus privilegiado para as referidas discussões, possíveis soluções, aconselháveis mudanças, evidenciando, enfim, posteriores conquistas. 
A PEDAGOGIA UNIVERSITÁRIA E A FORMACÃO DO PROFESSOR DE MATEMÁTICA:

UMA ANÁLISE DO PROJETO PEDAGÓGICO DO CURSO DA UFMS/CPTL

\section{REFERÊNCIAS}

BARDIN, L. Análise de Conteúdo. Lisboa: Edições 70. 2002.

BENITE, A. M. C. Considerações sobre o Enfoque Epistemológico do Materialismo Histórico-Dialético na Pesquisa Educacional. Revista Iberoamericana de Educación/Revista Ibero-america de Educação. n. 50, septiembre, 2019, p. 1-15. Disponível em: https://rieoei.org/historico/deloslectores/3024Benite. pdf Acesso em 7 de fev. de 2020.

BRASIL. Constituição de (1988). Constituição da República Federativa do Brasil. Brasília. Senado Federal, 1998.

BRASIL. Lei no 9.394, de dezembro de 1996 Brasília. Senado Federal, 1996. Disponível em: http:// www.planalto.gov.br/ccivil_03/leis/19394.htm Acesso em 28 de jul. de 2019.

BRASIL. Lei no 13.005, de junho de 2014. Senado Federal, 2014. Disponível em: https://legis.senado. leg.br/norma/584816/publicacao/15643219 Acesso em 28 de julho de 2019.

BRASIL. Conselho Nacional de Educação. Resolução $\mathbf{n}^{0}$ 2, de $\mathbf{1}^{\mathbf{0}}$ de julho de 2015. Brasilia. 2015. Disponível em: http://portal.mec.gov.br/docman/agosto-2017-pdf/70431-res-cne-cp-002-03072015pdf/file Acesso em 28 de jul. de 2019.

CUNHA, M. I. O Campo da Pedagogia Universitária: legitimidades e desafios. In: PINHO, S. Z. de (Org.). Formação de Educadores: dilemas contemporâneos. São Paulo: Editora Unesp, 2011. p. 177-191.

FIORENTINI, D.; SOUZA, A. J.; MELO, G. F. Saberes Docentes: Um Desafio para Acadêmicos e Práticos. In: GERALDI, C. (Org.). Cartografias do Trabalho Docente: Professor(a)-Pesquisador(a). 1. ed. Campinas: Mercado das Letras, ALB, 1998, p. 307-335.

FRIGOTTO, G. O Enfoque da Dialética Materialista Histórica na Pesquisa Educacional. IN: FAZENDA, I.C. A. (Org.) Metodologia da Pesquisa Educacional. São Paulo: Cortez, 1997, p. 69-90.

GIARETA, P. F. Nova Função Social para a Universidade do Século XXI: reflexos do pacto proposto pela Unesco para a política de formação de professores. 1 Ed. São Paulo: Novas Edições Acadêmicas, 2017.

GAUTHIER, C. et al. Por uma teoria da Pedagogia. Pesquisas contemporâneas sobre o saber docente. Unijuí: UNIJUÍ, 1998.

HABERMAS, J. Consciência Moral e Agir Comunicativo. Trad. Guido de Almeida. Rio de Janeiro: Tempo Brasileiro, 1989

MASETTO, M. T. (Org.). Docência na Universidade. Campinas: Papirus, 1998;

PALHANO, E. G. S. O saber docente: apontamentos para uma discussão. São Paulo, 1995. 158 f. Dissertação de Mestrado em História e Filosofia da Educação. Faculdade de Educação, PUC-SP.

RANGEL, L.; GIRALDO, V.; MACULAN, N. Matemática Elementar e Saber Pedagógico de Conteúdo - Estabelecendo Relações. Professor de Matemática Online. n. 1, v. 2, 2014.

SAVIANI, D. Os saberes implicados na formação do educador. In: BICUDO, M. A. V.; DA SILVA JUNIOR, C. A. Formação do Educador. 1. ed. São Paulo: Unesp, 1996, p. 145-155.

SHULMAN, L. S. Knowledge and teaching: Foundations of the new reform. Harvard Educational Review, n. 1, vol. 57, 1987.

SHULMAN, L. S. Those who understand: Knowledge growth in teaching. Educational Researcher, fev., 1986.

TARDIF, M.; LESSARD, C.; LAHAYE, L. Os Professsores face ao saber. Esboço de uma problemática do saber docente. Teoria \& Educação, Porto Alegre: Pannônica, n 4, 1991.

TARDIF, M. Saberes Profissionais dos Professores e Conhecimentos Universitários In: TARDIF, M. Saberes Docentes e Formação Profissional. 1. Ed.Campinas: Vozes, 2002, p. 245-276.

UFMS. Projeto Político Pedagógico do Curso de Matemática - Licenciatura. Três Lagoas: CPTL, 2019. 